\title{
The Teaching and Learning of Pharmacokinetic Subjects to Pharmacy Students: Review of Teaching Strategies
}

\author{
Mumtaz Hussain ${ }^{1}$, Shariza Sahudin 1,*, Izzati Yussof ${ }^{2}$, Norsavina Kaharudin ${ }^{3}$ \\ ${ }^{1}$ Faculty of Pharmacy, Universiti Technology MARA, Puncak Alam Campus, Selangor, MALAYSIA. \\ 2Pharmaceutical Services Division, Kuala Lumpur and Putrajaya Health Department, Jalan Cenderasari, 50590 Kuala Lumpur, MALAYSIA \\ VNI Scientific, Pusat Perniagaan Ixora, 70450 Senawang, Negeri Sembilan, MALAYSIA.
}

\begin{abstract}
A strong foundation in pharmacokinetics is essential not only to provide effective therapeutic outcomes for patients but also crucial to the pharmaceutical industry and the regulation of generic pharmaceuticals. Bioequivalence is an important regulatory concern for a pharmaceutical company in the manufacture of generic drugs. Pharmacokinetics should be mastered by pharmacy students to prepare them for their future careers, particularly in a hospital setting where pharmacists typically play a central role in clinical pharmacokinetics services. However, basic pharmacokinetics is sometimes not well-received by students because of its basis in mathematics and the relative difficulty in connecting basic concepts with clinical relevance. This narrative literature review examines the methodologies employed to teach pharmacokinetics, the move
\end{abstract}

towards computer-aided and distance learning, and the current software systems available to facilitate this. A better understanding of the limitations of current approaches is crucial to take steps to enhance the teaching and learning of such an important subject.

Key words: Pharmacokinetic software, Pharmacy education.

Correspondence

Dr. Shariza Sahudin,

Department of Pharmaceutics, Universiti Technology MARA, Puncak Alam Campus-42300 Selangor, MALAYSIA.

Email id: shariza2280@puncakalam.uitm.edu.my

DOI: 10.5530/jyp.2021.13.85

\section{INTRODUCTION}

The American Pharmaceutical Association defines pharmacokinetics as "the study of the kinetics of absorption, distribution, metabolism, and excretion (ADME) of drugs and their corresponding pharmacologic, therapeutic, or toxic responses in man and animals". ${ }^{1}$ This relatively broad definition hints at the central role played by pharmacokinetics not only in achieving positive therapeutic outcomes for clinical patients but also within drug development, where the function of a pharmaceutical dosage form is to ensure efficient delivery of an active pharmaceutical ingredient to its intended site of action. The application of pharmacokinetics studies thus includes the measurement of bioavailability and bioequivalence, identifying the effects of physiological and pathological factors on drug absorption and distribution, as well as the evaluation of drug-receptor interactions.

Pharmacokinetic principles play a central role in therapeutic drug monitoring (TDM), defined as the monitoring of drug concentrations within a patient to ensure that the optimum therapeutic effect of a drug is achieved without unwanted adverse effects. The rationale of implementing TDM is primarily for individualizing therapy in drugs with a narrow therapeutic index and hence marked patient-to-patient pharmacokinetic variability. Thus the main benefits of TDM lie in improving clinical efficacy and reducing toxicity. ${ }^{2}$ A clinical pharmacist must interpret patients' plasma concentrations, and with knowledge of patients' current clinical conditions, use this information to derive a dosing schedule that will maximize the therapeutic benefit of a drug.

A strong foundation in pharmacokinetics is essential not only to provide an effective TDM service but is also crucial to pharmaceutical industry and the regulation of generic pharmaceuticals. Bioequivalence is an important regulatory concern for a pharmaceutical company in the manufacture of generic medicines. In these cost-conscious times, cheaper generic medicines are chosen over pricier innovator brands, and in countries where healthcare is subsidized, governments often issue directives for generic prescribing. ${ }^{3}$ Bioequivalence studies provide a means of ensuring that generic medicines that enter the market are 'essentially similar' to the original formulation and are formulated in an equivalent pharmaceutical form to produce similar concentration-time profiles in the body. ${ }^{3}$ Bioequivalent studies are also important during the development of a different formulations from the initially marketed formulation, bypassing the need to conduct expensive clinical trials. ${ }^{3}$

Pharmacokinetics should be mastered by students to prepare them for their future careers, particularly in a hospital setting where pharmacists typically play a central role in clinical pharmacokinetics services. However, basic pharmacokinetics is sometimes not well-received by students because of its basis in mathematics and the relative difficulty in connecting basic concepts with clinical relevance. ${ }^{4}$ The present study is a narrative review that examines the methods, techniques, and strategies used to teach pharmacokinetics to undergraduate students, to gain a broad understanding and insight into the approaches used, and the benefits they may bring. In addition, the role of computer-aided learning is also examined, and the potential role of software to teach pharmacokinetics, in an attempt to ascertain whether a more IT-centric approach may offer improvements over traditional teaching methods.

\section{METHODOLOGY}

For this study, a literature review of the articles published between 2000 and 2020 was carried out, mainly through the Scopus and Web of Science databases. We searched in two database tags, namely "keyword tag" and "article title tag". Keywords focused on "pharmacokinetics", "education" ,"teaching and learning", "pharmacists", "TDM" and "bioequivalence". 
Thus, from the original articles and reviews, for educational studies, computer-based learning, TDM, and medical education, and higher education, 48 articles deemed related to the narrative review were selected.

\section{LITERATURE REVIEW}

In many universities, pharmacokinetics is taught using a multidisciplinary and integrated approach. First-year students are taught the basic concepts and theory of pharmacokinetics and pharmacodynamics within the realms of pharmacology, focusing on core concepts such as absorption, distribution, metabolism, and elimination (ADME). This is later augmented with a more detailed description of metabolic and elimination processes and drug behavior after distribution. In the second year of study, these foundation principles are built upon, with a greater emphasis on absorption and distribution, how pharmaceutical dosage forms can be formulated to optimize the bioavailability, and the equations behind compartment and non-compartmental analysis. In the third and fourth years, pharmacokinetics is taught in terms of medicines optimization with therapeutic goals, where students learn in detail the models used in TDM calculations. One common theme to all these streams is the conventional manner in which the subject is taught. Lectures in which material is delivered, and tutorials where students are provided equations and calculations for practice. One unfortunate side-effect of teaching the subject over the four years is the lack of coordination between the different streams, levels, and courses. This can result in a degree of confusion, where similar concepts are taught from the different perspectives of pharmacology, pharmaceutics, and clinical pharmacy.

TDM knowledge among healthcare personnel needs to be constantly updated as studies have explored the need to expand the practice of TDM for more drugs. These include antiretroviral agents, ${ }^{5}$ monoclonal antibodies, ${ }^{6}$ antifungals, antipsychotics (amisulpride), antituberculosis drugs, ${ }^{7}$ and even beta-lactam antibiotics, particularly in patients with variable pharmacokinetic profiles such as those who are obese, critically ill, febrile neutropenic and burn victims. ${ }^{8}$ Ensuring up-to-date knowledge among pharmacists and other healthcare personnel is essential to ensure the best-evidence practice is in place. Conveying new information and training may be problematic in settings with multiple facilities and large target audiences, where training may become time-consuming and resource-intensive. Recent developments in technology and teaching methods need to be utilized to provide a learning environment that is easy to access and available to all who need it. The following sections describe several strategies that have been employed to improve the education of pharmacokinetics and TDM in both university and workplace settings.

\section{TEACHING STRATEGIES IN HIGHER EDUCATION FACILITIES}

Educators around the globe have incorporated various strategies to improve teaching and learning processes. Particular efforts have been made to promote self-directed learning among students, increased incorporation of active learning, and a move away from passive learning. ${ }^{9}$ This trend is also being integrated into the teaching of pharmacokinetics. ${ }^{10}$

\section{Active Learning}

Active learning can be defined as student-centric instructional strategies that attempt to engage students with course materials and the learning process. ${ }^{11,12}$ The effectiveness of active learning is suggested to be due to limited by the attention span among students during lectures. Studies suggest that the average attention span during a typical lecture is approximately fifteen minutes, after which the number of students paying attention drops significantly, causing reduced retention of delivered material. ${ }^{11}$ On the simplest level of active learning, a lecturer can periodically pause their lecture to allow students time to clarify their notes. In a study by Ruhl et al. it was found that incorporating three twominutes breaks in a 45-min lecture improved short-term recall and longterm retention, as assessed by free-recall exercises and multiple-choice exams. ${ }^{13}$

Persky et al. developed games for the teaching of basic and clinical pharmacokinetics in their class. ${ }^{14}$ One such game involved solving a murder by the use of drugs, requiring students to find clues from the victim's concomitant medications and smoking habits. This allowed students to apply their knowledge in 'real-life' situations, promoting problem-solving, teamwork, and communication skills. ${ }^{14}$ Although some students perceived they did not learn as much compared to traditional lectures, a modest increase in examination scores was noted. ${ }^{14}$ An important component of the game was the debriefing session, where participants reflected on what they had learned and the decisions made throughout the game. ${ }^{14}$ The debriefing session is essential to ensure that students consciously reflect on what they had accomplished in the games, to prevent them from becoming an unproductive exercise. In addition to the pharmacokinetic-themed games, Persky described the utilization of a 'multi-faceted approach to improve the learning of pharmacokinetics, which also includes multimedia presentation modules, reflective writing assignments, and immediate feedback assessments. ${ }^{15}$ Of particular interest is reflective writing assignments, which requires students to write about any unanswered questions that arose during personal reading or class, related materials they learned in previous and concurrent classes, and allow them to address any personal experience issues with the materials covered in the course, including expectations and any fears. Lecturers can then address any important issues identified from the reflective writings anonymously in class discussions to benefit all students. ${ }^{15}$ Although this multi-faceted approach does not appear to significantly improve examinations scores ${ }^{15}$ it can however improve deep learning and other skills which may not be examinable but can equip students with generic skills including problem-solving, communication, and critical-thinking skills. ${ }^{15}$ Active learning is also a key element of other methods of learning, which are discussed below.

\section{Computer-Assisted Learning and e-Learning}

With the advancement of computer technology and the ever-increasing need for innovative teaching, CAL and electronic learning, or e-learning, have grown in popularity in recent decades. E-learning refers to any type of learning delivered electronically, and this includes computers, intranets, the internet, tablets, or smartphones. It has been defined as "instructions delivered electronically wholly by a web browser, through the internet or an intranet, through CD-ROM or DVD multimedia platforms". ${ }^{16}$ However, a common understanding of e-learning exclusively relates it to web-based training medium and is generally defined as learning conducted through an internet process, ${ }^{17}$ though definitions may vary among different authors. A large number of e-learning websites and apps are available online, for example, Coursera, Ted-Ed, SoloLearn, and Khan Academy. They provide various learning materials from motivational talks to entrepreneurship and even specialized topics such as computer programming and statistics.

CAL has the advantage of providing a flexible and interactive learning environment, allowing students more freedom in deciding when and where they want to learn. They can also progress at their own preferred pace, which may not be possible in a classroom setting where they will be forced to follow a fixed overall pace. This is advantageous for weaker students, as they can repeat, interrupt and resume lessons at 
will. ${ }^{18}$ The application of computers in teaching is especially suited for subjects that are visually intensive and difficult to conceptualize, as graphical representation is easily achievable with the help of images, videos, and graphs. In addition, it can reduce problems associated with diminishing attention spans in long lectures, as students will be able to control the progress of their learning at will. Multimedia lessons can also be programmed to include automated real-time feedback for teachers and learners to provide easy tracking of progress. ${ }^{17}$ Various studies have shown the effectiveness of utilizing computers in teaching. A review by Salter et al. concluded that e-learning in pharmacy education is effective at increasing knowledge, being equivalent to traditional learning and superior of course to no training. It helps to promote knowledge accumulation and retention, at least immediately after the study. ${ }^{17}$

E-learning enables students to participate in distance learning, making it possible to educate a large number of students from geographically diverse locations, thus linking more people into learning communities. It can save costs and valuable commuting time which students can use instead to improve their learning. CAL also benefits universities by allowing fewer face-to-face lectures, which may arguably reduce their workload. Once such distance learning applications have been set up, additional costs are minimal, and this can provide economical value over a long period. ${ }^{18}$ Examples of CAL and e-learning will be further discussed later in this chapter.

\section{Blended Learning}

Blended learning can be defined as the combination of traditional faceto-face learning and e-learning. It has been presented as a promising alternative approach as it is characterized as having the advantages of both traditional learning and e-learning. ${ }^{19}$ It is particularly valuable in avoiding learners' feelings of isolation in a virtual environment. ${ }^{19}$ Blended learning also allows higher participation of students doing parttime study or distance learning. The blended learning approach is an effective teaching method in various areas of pharmacy courses including microbiology, clinical pharmacy, pharmaceutical biotechnology, and pharmacokinetics. ${ }^{20,21-23}$

Edginton and Holbrook introduced a blended learning approach in the teaching of basic pharmacokinetics, involving a balanced integration of face-to-face learning and online instruction. ${ }^{20}$ Content delivery was achieved via online modules, followed by face-to-face problem-solving sessions to help students apply what they have learned. This session is paramount in allowing students to improve their understanding by clarifying any issues that arise following the self-learning online modules. ${ }^{20}$ In this approach, a balance between guidance from lecturers and students' self-initiative towards learning is essential, which helps train students to better manage their time.

\section{Problem-Based Learning}

PBL is a popular learning strategy introduced in the 1960s in medical education by Howard Barrows. It is an instruction method where problems are introduced at the beginning of the instruction cycle and used to provide the context for learning. ${ }^{11}$ Clinical problems are used as a starting point in the learning process, and students are expected to acquire new knowledge as they try to solve the problems, thus allowing students to link theories and applications. It incorporates an aspect of active learning and sometimes collaborative learning, involving a significant amount of self-directed learning among students. There is evidence that PBL improves long-term retention of knowledge compared to traditional instruction and promotes better study habits among students. ${ }^{11,24} \mathrm{PBL}$ is inductive and self-directed, thus providing explicit training in necessary skills that are required in students' future careers.
However, PBL may not be suitable for all types of learning. There are instances where students in PBL programs scored lower than students in traditional programs on tests of basic science. ${ }^{25}$ This may suggest that the amount of self-direction required by the students needs to be cautiously monitored, ${ }^{11}$ and direct learning in traditional programs may be more beneficial for the learning of basic science, at least about promoting academic achievement as measured by traditional exams. Although there is conflicting evidence in terms of academic achievement, PBL has been repeatedly shown to encourage positive students' attitudes, develop a deeper approach to learning, and allows longer retention of knowledge. ${ }^{11}$

\section{Team-Based Learning}

The primary objective of TBL is to ensure that students have the opportunity to practice applying course concepts and solve problems. ${ }^{26}$ Therefore, TBL is designed to equip students with both conceptual and procedural knowledge. In a TBL course, students are purposefully organized into permanent groups for the term. Students must study the assigned material before any in-class work as it will begin with a readiness assurance process (RAP). RAP consists of short tests on key concepts that students will need to complete both individually and later as a team. Immediate feedback is given after the team tests, where students are provided the opportunity to write evidence-based appeals if they disagree with the assessments. This is then followed by a session to allow the instructor to clarify any misperception evident from the tests and the appeals. After the RAP is completed, it is then followed by class activities and assignments that require students to practice with the course content. ${ }^{11,26}$

In a review by Ofstad and Brunner, TBL was found to be effective in medicine, nursing, and pharmacy. They concluded that that TBL can improve students' engagement, communication, team-building, and knowledge retention. ${ }^{26}$ The effectiveness of TBL in the learning of pharmacokinetics has been demonstrated by Persky and Franklin et al. ${ }^{27,28}$ Rather than spending class time for passive content delivery, TBL utilizes class time to develop important skills that students will need in their future careers. The main advantage of TBL lies in the improvement of positive attitudes, team-learning, and professionalism such as altruism, duty, accountability, and honesty. ${ }^{28}$ Franklin et al. have demonstrated the use of this hybrid approach in TBL for the teaching of a postgraduate pharmacokinetics course with students coming from geographically diverse populations. ${ }^{27}$ Adobe Connect was used as the online learning platform for geographically challenged students - some of whom are from a neighboring country - with several different sessions to choose from to fit around a students' schedule. It was found that the score for team RAP tests was higher in the online groups and there were positive interactions among team members despite the absence of face-to-face interactions. ${ }^{27}$

\section{Continuing Education in a Working Environment}

All health care professionals are faced with challenges to maintain proficiency and keep abreast with discoveries related to their work, and this also applies to pharmacists. Therefore, both professional associations and authorities in various countries have developed learning systems to maintain competency and provision of quality patient care. An example of such a system is continuing education (CE), which requires the collection of credit points by professionals to obtain continued certification or registration with professional bodies..$^{29}$ Approved learning activities such as workshops, lectures, and distance-learning courses are undertaken by a professional to obtain credit points, and the number of credit points is generally a reflection of the time spent. However, some countries award more credit points for undertaking activities that are deemed to provide 
greater impact on practice patterns, such as interactive workshops or assessments. ${ }^{29}$

Another approach is mandatory continuing professional development (CPD), which for example was introduced in 1998 by the Royal Pharmaceutical Society of Great Britain as a step forward from the previously employed CE. While elements of CE remain in CPD, a major difference is that every CPD entry has to be documented in a portfolio according to the elements of the CPD cycle; reflection, planning action, and evaluation. Pharmacists are required to state their learning objectives, plan learning activities, and set deadlines for achievements of the learning objectives and completion of the learning activities. They are then required to evaluate to what extent the learning objectives have been met, and provide examples of the application of the learning outcomes. ${ }^{29}$ Therefore, CPD can be seen as an active learning process as it includes reflection and requires pharmacists to actively engage in the learning process.

In a clinical setting, TDM continuing education tends to be aimed at ensuring appropriate TDM ordering/requests and blood sampling. ${ }^{30-32}$ This is generally targeted at physicians and nurses to prevent wastage and reduce patient discomfort due to unnecessary blood sampling. CE modules have also been developed to improve general knowledge in TDM among pharmacists and other healthcare personnel. For example, completion of a vancomycin-based CE resulted in a high score among the surveyed pharmacists, indicating good short-term knowledge retention following such learning exercises. ${ }^{31}$ Other healthcare professionals including physicians and nurses have also adopted the use of computers in an attempt to improve the appropriateness of TDM service in their facilities. ${ }^{30,32}$ Computerized ordering of TDM allows some degree of control to reduce inappropriate TDM requests, such as those inappropriately ordered before the steady-state achievement or ordering unnecessary or multiple peak concentrations requests, which have the potential to save over $\$ 40000$ per year in paper and reagent costs. ${ }^{30}$

\section{Computers as Tools for Teaching and Learning}

The current generation of student learners has grown up exposed to information technology. They have spent a great deal of time with smart devices, providing them with a source of a vast array of information in various forms. ${ }^{1}$ Educators must adopt these devices to become effective teaching instruments and make use of the benefits offered by the technological advancement of computers and smartphones. Unlike in previous decades, current technology provides portable, smart, and interactive touch screen displays, allowing flexibility and a more intuitive approach to learning that can be fully utilized for educational purposes. ${ }^{1}$ Greater graphics capacity with the potential of high-resolution videos provides high-quality video conferencing that can potentially replace classroom time and face-to-face discussions for distance learners, and allowing students and educators from geographically diverse areas to discuss together. Competition among telecommunication providers has pushed down the price of internet connections, making fast internet connections affordable to many students. This promotes the potential for e-learning, as accessibility is made easier and cheaper. E-learning is already popular within the corporate sector, where it is widely used to train new employees at a reduced cost. ${ }^{33,34}$ For example, International Business Machine (IBM) Corporation saved US\$200 million in 1999 by providing five times more training at one-third the cost compared to traditional training methods. ${ }^{34}$

As a mathematically oriented subject, the teaching of pharmacokinetics can benefit from computer applications with the use of graphical and interactive multimedia. Incorporating the use of computer software and multimedia in the teaching of pharmacokinetics enables students to become actively involved in the problem-solving exercise, performing complex calculations and generating graphs using spreadsheets and graphical programs with relative ease. ${ }^{35,36}$ This visual approach to learning may serve to assist students' to shift attention away from complex mathematical formulas and time-consuming manually drawn graphs, to greater a focus on understanding the relationships between the drug concentration-time curves and a patients' clinical outcomes. As mentioned previously, universities have already started to incorporate CAL programs or e-learning modules into their pharmacokinetics lessons. Some have adapted the use of video conferencing to perform online TBL in pharmacokinetics courses, which is an effective method, as evident from students' examination scores. ${ }^{27,28}$

\section{Pedagogical Principles and Considerations for CAL Development}

The Multimedia Effect Theory narrates that people learn more deeply with words and pictures than from words alone. This principle underlines the use of computers and multimedia and has been proven by various studies. ${ }^{37}$ It is thought that a better learning experience transpires when learners build a referential connection between verbal and non-verbal mental representations of the same items, thus maximizing memory retention for the presented items. ${ }^{37}$ The Dual Channel Theory assumes that humans possess separate information processing systems for visual (pictorial) and auditory (verbal) materials, each of which is processed by distinct visual and auditory systems respectively. ${ }^{37}$ It was found that students retain $20 \%$ of what they hear, and $40 \%$ of the information they see, but for students that can see, hear and interact with the learning material, the retention rate was significantly increased to $75 \%{ }^{38}$

The Spatial Contiguity Effect narrates that students can learn better when multiple sources of information are integrated, while the Temporal Contiguity Effect narrates that learning is improved when information, such as words and pictures, are presented simultaneously rather than successively. ${ }^{37}$ The Modality Effect suggests that learning is better from multimedia that consists of animation and narration rather than animation and text. ${ }^{37}$ All these relate to the potential effectiveness of $\mathrm{CAL}$ as a learning tool, as it allows a combination of images, sound, and animation to be used for information delivery.

Some studies have shown that CAL and e-learning can be as good or better than traditional instructor-led methods such as lectures, though several other studies are inconclusive. ${ }^{39,40}$ This ambiguity may be a result of the poor design of the CAL module rather than the ineffectiveness of CAL as a teaching and learning tool. The real value of a CAL module will only be achieved with careful development and implementation. Lecturers may be proficient in designing and delivering traditional lesson plans, but they may not be well equipped to deliver online courses effectively. ${ }^{41}$ The first time an electronic course is offered, the preparation is at least equal to in-class preparation time and requires a certain degree of familiarity and problem-solving skills with any authoring software being utilized. ${ }^{20}$ To ensure quality, institutions must cooperate by providing support and training for faculty professional development and acknowledge the time required for course preparation and maintenance. ${ }^{41}$

Learners must be able to quickly and easily navigate through CAL or e-learning modules to prevent unnecessary frustration due to poor design, technical errors, or malfunction in the forms of broken links and missing content links. Therefore, adequate information technology support from the institution is important for both learners and educators. ${ }^{41}$ Additional points to consider with CAL modules is that educators are typically unavailable for direct immediate learner consultation, and so ambiguity in instructions within the learning material must be avoided. Clear explanations and well-described tasks are critical to prevent additional workloads related to student inquiries, 
which are frequently underestimated ${ }^{20,41}$ It is also recommended to have one single academic calendar that integrates all course timetables and assignment deadlines to facilitate student organization and time management. ${ }^{41,42}$

Shifting from traditional learning to computer-based learning may create a degree of anxiety for some learners who are more familiar with classroom-based learning. This is more likely for adult learners, particularly as many may not be as comfortable with computers and smartphones in comparison with a younger generation of learners. ${ }^{41}$ This reemphasizes the importance of technical support as well as effective communication tools that students can use to discuss problems among their peers and lecturers, such as an online forum available for access by all students in the course. This also illustrates that fully online courses put learners at a disadvantage as students will often feel isolated within such a fully virtual environment. ${ }^{42}$ An effective online forum where students can interact may provide a solution, but learners tend to value face-to-face discussions, making blended-learning courses the preferred option over fully online courses..$^{20,42}$

Several occupational health-related concerns have been raised given the widespread application of e-learning, including repetitive stress injuries (RSI), bad posture, and eyestrain resulting from prolonged exposure to keyboards, mice, computer screens, and smartphone devices. ${ }^{43}$ This warrants further investigation, to further understand whether this should be a real concern for both learners and educators. However, 'Computer Vision Syndrome, which includes tired eyes, irritation, red eyes, blurred and double vision upon prolonged computer use has been well-documented. ${ }^{44}$ General precautions such as suitable lighting, antiglare filters, and ergonomic positioning of computer monitors may help to improve visual comfort. Regular breaks are also important both to prevent RSI, eye discomfort and ultimately allow improved retention of study materials. ${ }^{44}$

Any discussion of the use of computers in education is incomplete without mentioning the shift to remote teaching and learning brought on as a consequence of the Covid-19 pandemic. Not only do educators need to employ computers to deliver teaching material remotely, but they must also consider the student learning experience, the lack of experimental learning, and the challenges associated with online summative assessment. Though these considerations are beyond the remit of this review, however, they illustrate how a significant shift has occurred towards remote teaching and assessment, and this shift may result in permanent changes.

\section{Computer Applications for Pharmacokinetics and TDM}

The availability of computers has significantly accelerated the progress in both pharmacokinetics research, application, and teaching. ${ }^{45}$ The use of computer programs permits the rapid solution of complicated pharmacokinetics equations, thus allowing the utilization of more complex pharmacokinetic models. In addition, computers can help in the analysis of statistical data, graphical representation of data, pharmacokinetic model simulation and to provide a prediction of drug action $^{45}$ and data. One notable improvement brought by computers is the application of Bayesian statistics to assist in drug dosage modification and prediction, which was hailed as the 'gold standard' in TDM. ${ }^{46,47}$

There is a large variety of computer software dedicated to pharmacokinetics. Some software allows fitting of drug concentration-versus-time data to a variety of pharmacokinetic models and assists the user to choose the one that best describes the data statistically. ${ }^{45}$ Computer software may also provide a simulation that allows manipulation of parameters by the user, and the simulated model can be compared with experimental observed data. ${ }^{45}$ Software programs for clinical pharmacokinetic applications and teaching pharmacokinetics are also available. ${ }^{45}$
A list of pharmacokinetic-related software is available at the Pharmacokinetic and Pharmacodynamic Resources website (https:// www.pharmpk.com/soft.html). ${ }^{48}$ There are approximately 108 programs listed on the website, ranging from Microsoft Excel add-in functions for pharmacokinetic simulation to sophisticated programs that incorporate Bayesian analysis for dosage recommendation. A large proportion of these programs provide pharmacokinetics modeling for individuals, populations, as well pharmacokinetic-pharmacodynamic (PKPD) modeling and simulation. Some are dedicated to dosage adjustment in TDM, while a much smaller proportion is aimed at education and learning pharmacokinetics.

Several reviews have also been made to assess currently available software developed for TDM dosage adjustment. ${ }^{49,46,50}$ Fuchs et al. made a ranking of these software devices based on general characteristics of the software such as the Graphical User Interface (GUI), types of drugs supported, cost, availability of support, and ability to generate reports and integrate with laboratory information management system. The top five programs in their list are MwPharm $\odot$, TCIWorks, RxKinetics (a combination of APK and Kinetics $\odot$ ), RightDoseTM (previously known as MM-USC*PACK(), and T.D.M.S 2000TM. ${ }^{46}$ These software products are highly sophisticated with good usability and provide a Bayesian method for estimation of dose and pharmacokinetic parameters, where the patients' known clinical characteristics such as weight, gender, age, and creatinine clearance $(\mathrm{CrCl})$ are incorporated into the analysis to estimate the statistically most probable values of patient's pharmacokinetic parameters. T.D.M.S, MM-USC^PACK@ , DataKinetics, and Kinetidex are well-established software that was also featured in a review by Buffington et al. in $1993 .{ }^{50} \mathrm{MM}-\mathrm{USC}^{\star} \mathrm{PACK} \odot$ for example was first made available in 1973 and has gone through various reviewed versions. ${ }^{46}$ The review by Roberts et al. in 2014 highlighted several programs for antibiotics dosing that are also available in multiple platforms such as ID-ODS, DoseMe, First-dose, and CADDy Program. ${ }^{49}$ Apart from terminal-based software that requires computer installation, web-based programs were also reviewed in the article, such as First-dose and CADDy Program. However, First-dose could not be accessed as the website specified in the review article is now unavailable. CADDy is still available; it requires registration and is free to use.

A summary of the TDM software applications reviewed by Fuchs et al. is available in Table 1.0.6 Main aspects deemed relevant are highlighted and compared among the 12 software reviewed. Usability, platforms, and operating systems, drugs supported, cost and availability of support, and technical manuals were compared. It was noted that all 12 of the programs identified in the review run on Windows, with only three of them available for Mac OS (TCIWorks, JPKD, TDM for R), and four available for mobile devices (JPKD, Antibiotic Kinetics, APK, Data Kinetics).$^{46}$ TCIWorks and JPKD were written in Java, while others were mostly written in C++ and Pascal. ${ }^{46}$ In terms of usability, only RxKinetics (APK and Kinetics) and JPKD were rated as 'very easy' due to their user-friendliness, whilst others are deemed difficult to use. TDM for R is considered to be the least user-friendly as it is based on a commandline interface, while others use various designs of GUI to facilitate users' interaction with the software. ${ }^{46}$

Most of the reviewed programs in Table 1.0 are aimed at pharmacists or clinicians who are experienced in pharmacokinetics and TDM, as only a limited number, such as RxKinetics and Data Kinetics, provide information on drugs' pharmacokinetics and TDM. ${ }^{46}$ Nine of the listed software require a paid license for use, except for TCIWorks, JPKD, and TDM for R. TCIWorks has been reportedly discontinued, and TDM for $\mathrm{R}$ falls short in terms of user-friendliness. JPKD is free and provides both Bayesian and non-Bayesian calculation methods, but it does not support non-compartmental analysis for bioequivalence calculations. 


\begin{tabular}{|c|c|c|c|c|c|c|c|c|}
\hline Software & $\begin{array}{l}\text { Developing } \\
\text { Institution }\end{array}$ & $\begin{array}{l}\text { Platform/ } \\
\text { Operating } \\
\text { System }\end{array}$ & $\begin{array}{l}\text { Programming } \\
\text { language }\end{array}$ & $\begin{array}{c}\text { Availability } \\
\text { of GUI }\end{array}$ & $\begin{array}{c}\text { User } \\
\text { Friendliness }\end{array}$ & $\begin{array}{l}\text { Technical } \\
\text { Manual/ } \\
\text { Support }\end{array}$ & $\begin{array}{l}\text { Drugs } \\
\text { Supported }\end{array}$ & Cost \\
\hline MwPharm & $\begin{array}{l}\text { University of } \\
\text { Groningen, } \\
\text { MediWare }\end{array}$ & Windows & $\mathrm{C \#}$ & Yes & Need practice & Yes & $\begin{array}{l}>100 \text { drugs from } \\
\text { various classes }\end{array}$ & US $\$ 1,530$ \\
\hline $\begin{array}{l}\text { MM-USC } \\
\text { PACK }\end{array}$ & $\begin{array}{c}\text { University of } \\
\text { South California }\end{array}$ & Windows & $\mathrm{C}++/$ Matlab & Yes & Need practice & Sparse & $\begin{array}{l}\text { Antibiotics (sans } \\
\text { gentamicin), } \\
\text { Antiepileptics } \\
\text { (not phenytoin) }\end{array}$ & $\begin{array}{c}\text { US\$ } 595 \\
\text { (Donation) }\end{array}$ \\
\hline TCIWorks & $\begin{array}{l}\text { University } \\
\text { of Otago / } \\
\text { Queensland }\end{array}$ & $\begin{array}{l}\text { Windows/ } \\
\text { Mac/ Linux }\end{array}$ & Java & Yes & Need practice & $\begin{array}{l}\text { Starting } \\
\text { guide }\end{array}$ & $\begin{array}{l}\text { Aminoglycoside } \\
\text { antibiotics }\end{array}$ & Free \\
\hline $\begin{array}{l}\text { Antibiotic } \\
\text { Kinetics }\end{array}$ & $\begin{array}{l}\text { Creighton } \\
\text { University }\end{array}$ & $\begin{array}{l}\text { Windows/ } \\
\text { mobile device }\end{array}$ & Pascal & Yes & Very easy & Yes & Antibiotics & US\$ 125 \\
\hline APK & $\begin{array}{l}\text { Creighton } \\
\text { University }\end{array}$ & $\begin{array}{l}\text { Windows/ } \\
\text { mobile device }\end{array}$ & Pascal & Yes & Very easy & Yes & Antibiotics & US\$ 150 \\
\hline Kinetics & $\begin{array}{l}\text { Creighton } \\
\text { University }\end{array}$ & Windows & Visual Basic & Yes & Very easy & Yes & $\begin{array}{c}\text { Antibiotics, } \\
\text { Digoxin, } \\
\text { Aminophylline }\end{array}$ & US\$ 250 \\
\hline JPKD & $\begin{array}{l}\text { Kaohsiung } \\
\text { Medical } \\
\text { University }\end{array}$ & $\begin{array}{c}\text { Windows/ } \\
\text { mobile device } \\
\text { (not iOS)/ } \\
\text { Mac/ Linux }\end{array}$ & Java & Yes & Very easy & Yes & $\begin{array}{l}15 \text { drugs from } \\
\text { various classes } \\
\text { (eg: antibiotics, } \\
\text { antiepileptics) }\end{array}$ & Free \\
\hline TDM for $\mathrm{R}$ & $\begin{array}{l}\text { Kaohsiung } \\
\text { Medical } \\
\text { University }\end{array}$ & $\begin{array}{l}\text { Windows/ } \\
\text { Mac/ Linux }\end{array}$ & $\mathrm{R}$ & No & $\begin{array}{l}\text { Not user } \\
\text { friendly }\end{array}$ & No & $\begin{array}{l}17 \text { drugs from } \\
\text { various classes } \\
\text { (eg: antibiotics, } \\
\text { antiepileptics) }\end{array}$ & Free \\
\hline Kinetidex & $\begin{array}{l}\text { Thomson } \\
\text { Reuters }\end{array}$ & Windows & NA & Yes & Easy & Yes & $\begin{array}{l}6 \text { drugs } \\
\text { (antibiotics, } \\
\text { digoxin, } \\
\text { theophylline, } \\
\text { valproate) }\end{array}$ & $\begin{array}{c}\text { US\$ } 1,520 \\
\text { anually }\end{array}$ \\
\hline T.D.M.S 2000 & Healthware Inc & Windows & $\mathrm{C}++$ & Yes & Need practice & $\begin{array}{l}\text { Getting } \\
\text { started } \\
\text { guide }\end{array}$ & $\begin{array}{l}14 \text { drugs (eg: } \\
\text { antibiotics, } \\
\text { antiepileptics, } \\
\text { digoxin, } \\
\text { theophylline) }\end{array}$ & $\begin{array}{l}\text { US\$ } 600 \\
\text { anually }\end{array}$ \\
\hline Data Kinetics & MDK Inc & $\begin{array}{l}\text { Windows/ } \\
\text { mobile device } \\
\text { (no iOS) }\end{array}$ & NA & Yes & Easy & Yes & $\begin{array}{l}10 \text { drugs (eg: } \\
\text { antibiotics, } \\
\text { digoxin, } \\
\text { phenytoin) }\end{array}$ & US\$ 900 \\
\hline RADKinetics & NA & $\begin{array}{c}\text { Windows } \\
\text { (older version) }\end{array}$ & NA & Yes & Easy & No & $\begin{array}{l}\text { Gentamicin and } \\
\text { vancomycin }\end{array}$ & US\$ 100 \\
\hline
\end{tabular}

Several other software packages have also been developed to assist clinicians in conducting bioequivalence studies. Examples of established software include Phoenix WinNonlin, Kinetica, Bear, and EquivTest, which employ non-compartmental analysis for the determination of bioequivalence. ${ }^{48}$ Phoenix WinNonlin is an enhanced version of WinNonlin, with an improved GUI and integrated functions such as PKPD modeling and a validation module. Bear is a validated opensource software package that can assist in sample size estimation and provides statistical analyses relevant to bioequivalence. Pmetrics is a software developed by the University of South California, the same developer for MM-USC`PACK@ , and utilizes nonparametric methods for bioequivalence analysis, it is still currently in the validation stage. ${ }^{51}$
Examples of software for the teaching and learning of pharmacokinetics are fairly limited in the literature. A recent example is Maxsim2, which was developed for computer-assisted learning of pharmacokinetics and pharmacodynamic. ${ }^{52}$ It incorporates interactive simulations that allow students to adjust various parameters such as Vd, CL, blood flow, and tissue-to-blood partition coefficient and observe the effects of the changing parameters..$^{52}$ The price for a single-user license was quoted at $€ 465$, while a multiple-user license for up to 10 users costs $€ 2412$. PKSIM allows pharmacokinetic simulations of drugs using (up to) three-compartment models and incorporates simulations for drugs with both linear and non-linear pharmacokinetics. Simulations can be made following single or multiple dosing, and the effects of both parent drugs and metabolites can be studied..$^{53}$ Other software such as PharmaCalc tends to focus on PKPD simulation to assist in teaching PKPD modeling 
using multi-compartment models, ${ }^{54}$ while the more sophisticated systems can also be used in drug design. ${ }^{55,56}$ Another notable PKPD simulation tool is EDSIM++, an object-oriented modeling tool developed by MediWare, the same developer of MwPharm. ${ }^{57}$ The process of PKPD is represented as objects that can be dragged and dropped to the desktop and connected. EDSIM++ does not require programming for normal functions, but users with programming ability in C\# can create new PKPD objects and add them to the library or even create a new model.

Practical Pharmacokinetics by ClinPharm International focuses on the teaching of pharmacokinetics, with an emphasis on TDM. ${ }^{58}$ It has two main components, a teaching component and another focuses on practice. The package has won the Innovation in Teaching Award by the American Association of Colleges Pharmacy and includes a small database on special populations. ${ }^{59}$ However, the software package was developed for an older version of Windows (3.1/95/98) and it is unclear if it has since been updated.

In summary, although numerous pharmacokinetics software programs are available, most are aimed at either PKPD simulation or dosage adjustment for TDM service in a clinical setting. Some have been discontinued, while others are only compatible with older versions of Windows. The cost of software is also a limiting factor, with prices reaching over US $\$ 1500$ for a full license for some. Currently available software do not provide a one-stop center for the learning of pharmacokinetics, as most are only focused on a specific aspects such as pharmacokinetic modeling or TDM for dosage optimization.

\section{CONCLUSION}

Innovation in teaching is a good way forward to improve students' understanding of pharmacokinetics as it is often not well-received due to its basis in mathematics and the difficulty in linking basic concepts with clinical relevance. Various strategies have been adopted to improve learning experiences, with an emphasis on active learning to improve long-term retention and promote skills important for students' future careers, such as interpersonal interactions, self-esteem, and learning attitude. Continuous education and training in the workplace can directly help to reduce costs and increase the effectiveness of TDM service. With the advancement of technology, the use of computers as teaching tools provides various opportunities with an interactive learning solution for a wider population regardless of geographical barriers. CAL and e-learning have exciting potential, but careful implementation with proper training, maintenance, and cooperation across departments is essential for success.

\section{ACKNOWLEDGEMENT}

The authors would like to thank VNI Scientific (100-TNCPI/ PRI16/6/2(056/2020) for financial support.

\section{CONFLICT OF INTEREST}

The authors declare that there is no conflict of interest.

\section{ABBREVIATIONS}

TDM: Therapeutic Drug Monitoring; ADME: Adsorption Distribution Metabolism Elimination; CAL: Computer Aided Learning; TBL Team Based Learning; CE: Continuing Education; RAP: Readiness Assurance Process; PBL: Problem Based Learning; CE: Continuing Education; CPD: Continuing Professional Development; PKPD: PharmacokineticPharmacodynamic; RSI: Repetitive Stress Injuries; E-learning: Electronic Learning; GUI: Graphical User Interface; VD: Volume of Distribution; CL: Clearance; IT: Information Technology; CrCL: Creatinine Clearance.

\section{REFERENCES}

1. Jambhekar SS, Breen PJ. Basic pharmacokinetics. London: Pharmaceutical Press; 2009.

2. Ye ZK, Tang HL, Zhai SD. Benefits of therapeutic drug monitoring of vancomycin: a systematic review and meta-analysis. PLOS ONE. 2013;8(10):e77169. doi: 10.1371/journal.pone.0077169, PMID 24204764.

3. Pearce GA, McLachlan AJ, Ramzan I. Bioequivalence: How, Why, and What Does it Really Mean? J Pharm Pract Res. 2004;34(3):195-200. doi: 10.1002/ jppr2004343195.

4. Persky AM, Pollack GM. A hybrid jigsaw approach to teaching renal clearance concepts. Am J Pharm Educ. 2009;73(3):49. doi: 10.5688/aj730349, PMID 19564992.

5. Wertheimer BZ, Freedberg KA, Walensky RP, Yazdanapah $Y$, Losina E. Therapeutic drug monitoring in HIV treatment: a literature review. HIV Clin Trials. 2006;7(2):59-69. doi: 10.1310/hct.2006.7.2.004, PMID 16798621.

6. Oude Munnink TH, Henstra MJ, Segerink LI, Movig KL, Brummelhuis-Visser $P$. Therapeutic drug monitoring of monoclonal antibodies in inflammatory and malignant disease: translating TNF-alpha experience to oncology. Clin Pharmacol Ther. 2016;99(4):419-31. doi: 10.1002/cpt.211, PMID 26265133.

7. Mota L, Al-Efraij K, Campbell JR, Cook VJ, Marra F, Johnston J. Therapeutic drug monitoring in anti-tuberculosis treatment: a systematic review and metaanalysis. Int J Tuberc Lung Dis. 2016;20(6):819-26. doi: 10.5588/ijtld.15.0803, PMID 27155187.

8. Roberts JA, Norris R, Paterson DL, Martin JH. Therapeutic drug monitoring of antimicrobials. Br J Clin Pharmacol. 2012;73(1):27-36. doi: 10.1111/j.13652125.2011.04080.x, PMID 21831196

9. Blouin RA, Riffee WH, Robinson ET, Beck DE, Green C, Joyner PU, Persky AM, Pollack GM. Roles of innovation in education delivery. Am J Pharm Educ. 2009;73(8):154. doi: 10.5688/aj7308154, PMID 20221347.

10. Dupuis RE, Persky AM. Use of case-based learning in a clinical pharmacokinetics course. Am J Pharm Educ. 2008:72(2):29. doi: 10.5688/aj720229, PMID 18483597.

11. Prince M. Does active learning work? A review of the research. J Eng Educ. 2004;93(3):223-31. doi: 10.1002/j.2168-9830.2004.tb00809.x.

12. Franklin AS, Markowsky S, De Leo J, Normann S, Black E. Using team-based learning to teach a hybrid pharmacokinetics course online and in class. Am J Pharm Educ. 2016;80(10):171. doi: 10.5688/ajpe8010171, PMID 28179720.

13. Ruhl KL, Hughes $C A$, Schloss PJ. Using the pause procedure to enhance lecture recall. Teach Educ Spec Educ. 1987;10(1):14-8. doi: 10.1177/088840648701000103.

14. Persky AM, Stegall-Zanation J, Dupuis RE. Students perceptions of the incorporation of games into classroom instruction for basic and clinical pharmacokinetics. Am J Pharm Educ. 2007;71(2):21. doi: 10.5688/aj710221, PMID 17533430

15. Persky AM. Multi-faceted approach to improve learning in pharmacokinetics Am J Pharm Educ. 2008;72(2):36. doi: 10.5688/aj720236, PMID 18483602

16. Assareh A, Hosseini Bidokht MH. Barriers to e-teaching and e-learning. Procedia Comput Sci. 2011;3:791-5. doi: 10.1016/j.procs.2010.12.129.

17. Salter SM, Karia A, Sanfilippo FM, Clifford RM. Effectiveness of e-learning in pharmacy education. Am J Pharm Educ. 2014;78(4):83. doi: 10.5688/ajpe78483, PMID 24850945

18. Greenhalgh T. Computer assisted learning in undergraduate medical education. BMJ. 2001;322(7277):40-4. doi: 10.1136/bmj.322.7277.40, PMID 11141156

19. Liu Q, Peng W, Zhang F, Hu R, LiY, Yan W. The effectiveness of blended learning in health professions: systematic review and meta-analysis. J Med Internet Res. 2016;18(1):e2. doi: 10.2196/jmir.4807, PMID 26729058.

20. Edginton A, Holbrook J. A blended learning approach to teaching basic pharmacokinetics and the significance of face-to-face interaction. Am J Pharm Educ. 2010;74(5). doi: 10.5688/aj740588, PMID 20798797.

21. Sancho P, Corral R, Rivas T, Gonzalez MJ, Chordi A. C. Tejedor C.A blended learning experience for teaching microbiology. Am J Pharm Educ. 2006;70(5).

22. Zapantis A, Machado C, Nemire R, Leung S. An elective course in adult acute care medicine using a hybrid delivery system. Am J Pharm Educ. 2008;72(5):105. doi: 10.5688/aj7205105, PMID 19214259.

23. Crouch MA. An advanced cardiovascular pharmacotherapy course blending online and face-to-face instruction. Am J Pharm Educ. 2009;73(3):51. do: 10.5688/aj730351, PMID 19564994

24. Norman GR, Schmidt HG. The psychological basis of problem-based learning: a review of the evidence. Acad Med. 1992;67(9):557-65. doi: 10.1097/00001888199209000-00002, PMID 1520409.

25. Albanese MA, Mitchell S. Problem-based learning: a review of literature on its outcomes and implementation issues. Acad Med. 1993;68(1):52-81. doi: 10.1097/00001888-199301000-00012, PMID 8447896. 
26. Michaelsen LK, Sweet M. The essential elements of team-based learning. New Dir Teach Learn. 2008;2008(116):7-27. doi: 10.1002/tl.330.

27. Ofstad W, Brunner LJ. Team-based learning in pharmacy education. Am J Pharm Educ. 2013;77(4):70. doi: 10.5688/ajpe77470, PMID 23716738.

28. Persky AM. The impact of team-based learning on a foundational pharmacokinetics course. Am J Pharm Educ. 2012;76(2):31. doi: 10.5688/ ajpe76231, PMID 22438603

29. Driesen A, Verbeke K, Simoens S, Laekeman G. International trends in lifelong learning for pharmacists. Am J Pharm Educ. 2007;71(3):52. doi: 10.5688/ aj710352, PMID 17619652.

30. Bates DW, Soldin SJ, Rainey PM, Micelli JN. Strategies for physician education in therapeutic drug monitoring. Clin Chem. 1998;44(2):401-7. doi: 10.1093/ clinchem/44.2.401, PMID 9474051.

31. Phillips CJ, Wisdom AJ, Eaton VS, Woodman RJ, McKinnon RA. The impact of a pilot continuing professional development module on hospital pharmacists preparedness to provide contemporary advice on the clinical use of vancomycin. SpringerPlus. 2016;5:331. doi: 10.1186/s40064-016-1966-2, PMID 27064954.

32. Melanson SE, Mijailovic AS, Wright AP, Szumita PM, Bates DW, Tanasijevic MJ An intervention to improve the timing of vancomycin levels. Am J Clin Pathol. 2013;140(6):801-6. doi: 10.1309/AJCPKQ6EAH7OYQLB, PMID 24225746.

33. Govindasamy T. Successful implementation of e-learning. Internet Higher Educ. $2001 ; 4(3-4): 287-99$. doi: 10.1016/S1096-7516(01)00071-9.

34. Strother JB. An Assessment of the Effectiveness of e-learning in Corporate Training Programs. IRRODL. 2002;3(1). doi: 10.19173/irrodl.v3i1.83.

35. Leblanc PP, Aiache JM. Problem-based and computer-assisted-learning of pharmacokinetics. Am J Pharm Educ. 1994;58(1).

36. Munar MY, Singh H, Belle D, Brackett CC, Earle SB. The use of wireless laptop computers for computer-assisted learning in pharmacokinetics. Am J Pharm Educ. 2006;70(1):4. doi: 10.5688/aj700104, PMID 17136147.

37. Mayer RE. Multimedia learning. Psychol Learn Motiv. 2002;41:85-139. doi: 10.1016/S0079-7421(02)80005-6.

38. Fletcher JD. Effectiveness and cost of interactive videodisc instruction in defense training and education. Def Tech Inf Cent.

39. Ruiz JG, Mintzer MJ, Leipzig RM. The impact of e-learning in medical education. Acad Med. 2006;81(3):207-12. doi: 10.1097/00001888-200603000-00002, PMID 16501260

40. Karaksha A, Grant G, Davey AK, Anoopkumar-Dukie S. Development and evaluation of computer-assisted learning (CAL) teaching tools compared to the conventional didactic lecture in pharmacology education. In: EduLearn: 3rd International Conference on Education and New Learning Technologies. Vol. 11; 2011. p. 3580-9.

41. Wilbur K. Evaluating the online platform of a blended-learning pharmacist continuing education degree program. Med Educ Online. 2016:21(1):31832. doi: 10.3402/meo.v21.31832, PMID 27282277.

42. Margolis AR, Porter AL, Pitterle ME. Best practices for use of blended learning. Am J Pharm Educ. 2017;81(3):49. doi: 10.5688/ajpe81349, PMID 28496269.

43. Becker K, Newton C, Sawang S. A learner perspective on barriers to e-learning.
Aust J Adult Learn. 2013;53(2).

44. Blehm C, Vishnu S, Khattak A, Mitra S, Yee RW. Computer vision syndrome: a review. Surv Ophthalmol. 2005;50(3):253-62. doi: 10.1016/j. survophthal.2005.02.008, PMID 15850814.

45. Shargel L, Wu-Pong S. Yu ABC. Applied biopharmaceutics and pharmacokinetics. 5th ed. New York: McGraw-Hill; 2005.

46. Fuchs A, Csajka C, ThomaY, Buclin T, Widmer N. Benchmarking therapeutic drug monitoring software: a review of available computer tools. Clin Pharmacokinet. 2013;52(1):9-22. doi: 10.1007/s40262-012-0020-y, PMID 23196713.

47. Thomson $\mathrm{AH}$, Whiting B. Bayesian parameter estimation and population pharmacokinetics. Clin Pharmacokinet. 1992;22(6):447-67. doi: 10.2165/00003088-199222060-00004, PMID 1587057.

48. Bourne DWA. Pharmacokinetic software; 2017 [online] [cited May 29, 2018] Available from: https://www.pharmpk.com/soft.html.

49. Roberts JA, Abdul-Aziz MH, Lipman J, Mouton JW, Vinks AA, Felton TW Hope WW, Farkas A, Neely MN, Schentag JJ, Drusano G, Frey OR, Theuretzbacher $U$, Kuti JL. Individualised antibiotic dosing for patients who are critically ill: challenges and potential solutions. Lancet Infect Dis. 2014;14(6):498-509. doi: 10.1016/S1473-3099(14)70036-2.

50. Buffington DE, Lampasona $\mathrm{V}$, Chandler $\mathrm{MH}$. Computers in pharmacokinetics Choosing software for clinical decision making. Clin Pharmacokinet. 1993;25(3):205-16. doi: 10.2165/00003088-199325030-00004, PMID 8222461.

51. Glerum PJ, Yu Y, Yamada W, Neely M, Maliepaard M, Burger D, Neef C Robustness of the conclusion of bioequivalence; A non-parametric comparison. Clin Ther. 2017;39(8):e63-4. doi: 10.1016/j.clinthera.2017.05.196.

52. Gabrielsson J, Andersson K, Tobin G, Ingvast-Larsson C, Jirstrand M. Maxsim2 - Real-time interactive simulations for computer-assisted teaching of pharmacokinetics and pharmacodynamics. Comput Methods Programs Biomed. 2014:113(3):815-29. doi: 10.1016/j.cmpb.2013.12.006, PMID 24461798.

53. Li RC, Wong SL, Chan KK. Expanded version of PKSIM for pharmacokinetic simulations of both metabolite and parent drugs. Am J Ther. 1997:4(1):16-22 doi: 10.1097/00045391-199701000-00004, PMID 10423585.

54. Kramer SD. PharmaCalc: pharmacokinetic simulations; 2018 [online] [cited May 29, 2018]. Available from: http://www.biopharmacy.ethz.ch/simulations.html.

55. Thakker KM. Pharmacokinetic-pharmacodynamic modelling and simulation using the electrical circuit simulation program spice2. Biopharm Drug Dispos. 1984;5(4):315-33. doi: 10.1002/bdd.2510050404.

56. Lötsch J, Kobal G, Geisslinger G. Programming of a flexible computer simulation to visualize pharmacokinetic-pharmacodynamic models. Int J Clin Pharmaco Ther. 2004;42(1):15-22. doi: 10.5414/cpp42015, PMID 14756382.

57. MEDIWARE information systems. Edsim++; 2014 [online] [cited May 29, 2018] Available from: http://www.mediware.cz/en/edsim-about-system.

58. Hussein G. Pharmacokinetics practical pharmacokinetics: A curriculum-based interactive multimedia computer Program forTeaching Clinical Pharmacokinetics. Ther Drug Monit. 1996;18(4). doi: 10.1097/00007691-199608000-00034.

59. Charles BG, Duffull SB. Pharmacokinetic software for the health sciences: choosing the right package for teaching purposes. Clin Pharmacokinet 2001;40(6):395-403. doi: 10.2165/00003088-200140060-00001, PMID 11475465

Article History: Received: 03-08-2021; Revised: 28-09-2021; Accepted: 17-10-2021.

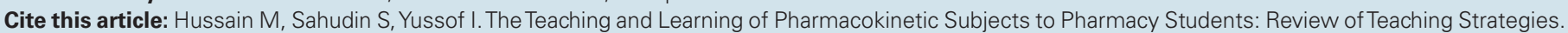
J Young Pharm. 2021;13(4):327-34. 